\title{
Inhalative and intravenous stimulation of soluble guanylate cyclase reduces pulmonary vascular resistance and increases cardiac output in experimental septic shock
}

\author{
NILS KRONAS ${ }^{1,2}$, BIRTE PETERS ${ }^{1}$, HANS PETER RICHTER $^{3}$, \\ ALWIN EDUARD GOETZ ${ }^{1,4}$ and JENS CHRISTIAN KUBITZ ${ }^{1,4}$ \\ ${ }^{1}$ Cardiovascular Research Center, University Medical Center Hamburg-Eppendorf, D-20246 Hamburg; \\ ${ }^{2}$ Department of Internal Medicine, Diakonissenkrankenhaus Flensburg, D-24939 Flensburg; \\ ${ }^{3}$ Department of Anaesthesiology, Munich Municipal Hospital, D-81545 Munich; ${ }^{4}$ Department of Anaesthesiology, \\ University Medical Center Hamburg-Eppendorf, D-20246 Hamburg, Germany
}

Received July 15, 2016; Accepted October 4, 2016

DOI: $10.3892 / \mathrm{etm} .2017 .4149$

\begin{abstract}
The effects of inhaled and intravenous application of a guanylate cyclase stimulator (BAY 41-8543) on pulmonary vascular resistance (PVR) and cardiac output (CO) were investigated in an experimental model of septic shock. Following induction of septic shock, anaesthetized pigs $(n=31)$ were randomly place into two groups receiving different interventions. Animals in the first group received intravenous BAY 41-8543 (0.6 mg), inhalative BAY 41-8543 (6 mg) or a placebo. In the second group, the dosage of BAY 41-8543 was increased two-fold or combined with inhalation of nitric oxide (iNO). Intravenous and inhaled administration of BAY 41-8543 resulted in a significantly $(\mathrm{P}<0.05)$ reduced PVR and increased $\mathrm{CO}$ compared with the placebo. Increasing the dosage of BAY 41-8543 or combining it with iNO did not further decrease PVR. The results of the present study indicate that BAY 41-8543 effectively reduces PVR and increases $\mathrm{CO}$ in septic shock, through inhaled or intravenous routes of administration.
\end{abstract}

\section{Introduction}

Acute right ventricular (RV) failure requires immediate causative and supportive treatment. RV function has to be supported by optimizing preload, afterload and contractility. As the RV has little pressure capacity, a minor increase in RV afterload may lead to a major deterioration in RV function. Conversely, the regulation of the pulmonary vascular tone is complex. The

Correspondence to: Professor Jens Christian Kubitz, Department of Anaesthesiology, University Medical Center Hamburg-Eppendorf, 52 Martinistr, D-20246 Hamburg, Germany

E-mail: jkubitz@uke.de

Key words: pulmonary hypertension, heart failure, septic shock, guanylate cyclase two primary methods to induce pulmonary vasodilation are through a prostacyclin-dependent cyclic adenosine monophosphate (cAMP) increase and nitric oxide (NO)-induced cyclic guanosine monophosphate (cGMP) increase. Endogenous NO augments the cGMP production from guanosine triphosphate by stimulation of the enzyme soluble guanylate cyclase (sGC) (1). cGMP modulates the activity of protein kinases and phosphodiesterases, thereby inducing vasodilatation and inhibiting remodelling, possibly by stimulating collagenolytic and elastolytic activity in pulmonary vessels (2).

The activity of sGC is increased by NO-dependent and -independent stimulators. These pulmonary vasodilators have been investigated in experimental models of pulmonary arterial hypertension (PAH) (3), pressure and hypoxia induced myocardial injury, ischemia-reperfusion injury of the lung (4), and in patients with PAH $(5,6)$ or decompensated heart failure (7). Pulmonary vasodilators have been shown to reduce pulmonary vascular resistance (PVR) and improve remodelling following myocardial injury $(8,9)$.

In endotoxemia and septic shock, the RV faces two obstacles (10), an increase in PVR due to increased plasma levels of endothelin-1 (11) and proinflammatory cytokines such as interleukin 1- $\beta$, interleukin 6 and tumor necrosis factor $\alpha$, and a decrease in contractility, known as septic cardiomyopathy. Therefore, reducing RV afterload is a promising strategy to restore RV output (12). However, there are no clear recommendations for how this goal may be achieved in patients with sepsis. Inotropic support with systemic administration of a $\beta_{2}$-agonist, such as dobutamine, or phosphodiesterase inhibitors, such as milrinone, simultaneously reduces systemic vascular resistance and increases contractility. Specific vasodilation of the pulmonary vascular system may be achieved with intravenous or inhaled administration of prostanoids, or through inhaled nitric oxide (iNO) (13).

The present study investigated the effects of sGC stimulation with BAY 41-8543 on PVR and CO in an experimental model of endotoxin-induced septic shock, hypothesizing that a decreased PVR would be associated with increased CO. In addition, the efficacy of intravenous and inhaled administration 
of BAY 41-8543 were compared. Furthermore, the effects of an increase in the dosage (2-fold) of BAY 41-8543 and the simultaneous administration of iNO were studied.

\section{Materials and methods}

Experimental animals. Thirty-one German female Landrace pigs (age, 6 months; weight, $25 \pm 2 \mathrm{~kg}$ ) were studied. Animals were obtained from the local veterinary institute for animal research (University of Hamburg, Hamburg, Germany), where they were housed in small groups for $\geq 3$ days prior to the study in indoor and outdoor houses with free access to water and food as appropriate to their species. Study protocols were approved by the local Governmental Commission on the Care and Use of Animals (Behörde für Soziales, Familie, Gesundheit und Verbraucherschutz, Lebensmittelsicherheit und Veterinärwesen, Hamburg, German; file no.01/10; approval no. 21.04.2010). All animals were cared for in compliance with the Guide for the Care and Use of Laboratory Animals, published by the National Research Council (US) Committee for the Update of the Guide for the Care and Use of Laboratory Animals (14). Surgical preparation and measurements were performed under anaesthesia. Following the completion of the study, animals were sacrificed by anaesthetic overdose by right atrial injection of $40 \mathrm{mmol}$ potassium chloride.

Anaesthesia. Animals were anesthetised prior to measurements. Following intramuscular injection of midazolam $\left(0.5 \mathrm{mg} \mathrm{kg}^{-1}\right)$ (Roche Pharma AG, Grenzach-Wyhlen, Germany), ketamine (10 mg kg-1) (Inresa Arzneimittel GmbH, Freiburg, Germany) and azaperone (10-15 mg kg-1; Lilly Deutschland GmbH, Bad Homburg, Germany), an ear-vein was cannulated and anaesthesia maintained by continuous administration of fentanyl (0.01 mg kg-1 $\mathrm{h}^{-1}$ ) (Janssen-Cilag GmbH, Neuss, Germany), midazolam (0.5 $\left.\mathrm{mg} \mathrm{kg}^{-1} \mathrm{~h}^{-1}\right)$ and propofol $(6 \mathrm{mg}$ $\mathrm{kg}^{-1} \mathrm{~h}^{-1}$ ) (B. Braun Melsungen AG, Melsungen, Germany). Then, a surgical tracheotomy was performed and a cannula (ID, 8-9 mm; Tracheoflex; Fahl Medizintechnik, Cologne, Germany) was inserted. The animals were mechanically ventilated (Zeus Infinity Empowered; Draegerwerk AG \& Co. $\mathrm{KGaA}$, Lübeck, Germany) with a mixture of $30 \%$ oxygen in air at a tidal volume of $10 \mathrm{ml} \mathrm{kg}^{-1}$, an inspiration to expiration ratio of 1:2 and a positive end-expiratory pressure (PEEP) of $5 \mathrm{~cm} \mathrm{H}_{2} \mathrm{O}$. The respiratory rate was adjusted to maintain an arterial $\mathrm{CO}_{2}$ tension of $<50 \mathrm{mmHg}$. Oxygen was altered as needed for an arterial oxygen tension of $90 \mathrm{mmHg}$ and PEEP was adjusted following Acute Respiratory Distress Syndrome network guidelines (15). Sodium chloride $(0.9 \%)$ solution was infused continuously at a rate of $10 \mathrm{ml} \mathrm{kg}^{-1} \mathrm{~h}^{-1}$.

Haemodynamic and blood gas measurements. Following surgical preparation of the left carotid artery, an electronic Micro-Tip pressure catheter (SPC-350; Millar, Inc., Houston, TX, USA) was positioned within the descending aorta for arterial pressure recordings. A 7-F central venous catheter (B. Braun Melsungen AG, Melsungen, Germany) was inserted through the right external jugular vein for medication and central venous pressure recordings. The left external jugular vein was used to position a $7 \mathrm{~F}$ Swan-Ganz catheter (131F7; Edwards Lifesciences, Unterschleissheim, Germany) for
Table I. Haemodynamic measurements prior to (BASE1) and during (SHOCK) septic shock.

\begin{tabular}{|c|c|c|}
\hline $\begin{array}{l}\text { Haemodynamic } \\
\text { parameter }\end{array}$ & BASE1 & SHOCK \\
\hline $\operatorname{HR}\left(\min ^{-1}\right)$ & $88.5( \pm 18.0)$ & $128.1( \pm 33.8)^{\mathrm{a}}$ \\
\hline MAP (mmHg) & $92.5( \pm 14.3)$ & $56.8( \pm 3.9)^{\mathrm{a}}$ \\
\hline MPAP (mmHg) & $27.1( \pm 6.9)$ & $37.9( \pm 6.8)^{\mathrm{a}}$ \\
\hline $\mathrm{CO}\left(1 \min ^{-1}\right)$ & $3.0( \pm 0.9)$ & $2.0( \pm 0.5)^{\mathrm{a}}$ \\
\hline PVR (dynes s ${ }^{-1} \mathrm{~cm}^{-5}$ ) & $524.2( \pm 212.3)$ & $1257.4( \pm 402.1)^{\mathrm{a}}$ \\
\hline SVR (dynes s-1 $\mathrm{cm}^{-5}$ ) & $2417.4( \pm 750.8)$ & $2155.5( \pm 594.4)$ \\
\hline $\mathrm{SvO}_{2}(\%)$ & $75.6( \pm 7.8)$ & $52.3( \pm 12.8)^{\mathrm{a}}$ \\
\hline $\mathrm{Lac}(\mathrm{mmol} / \mathrm{l})$ & $1.5( \pm 1.1)$ & $2.3( \pm 0.8)^{\mathrm{a}}$ \\
\hline $\mathrm{PaO}_{2} / \mathrm{FiO}_{2}(\mathrm{mmHg})$ & $493.9( \pm 74.7)$ & $330.3( \pm 127.3)^{\mathrm{a}}$ \\
\hline
\end{tabular}

The results are presented as mean ( \pm standard deviation). HR, heart rate; MAP, mean arterial pressure; MPAP, mean pulmonary artery pressure; $\mathrm{CO}$, cardiac output; PVR, pulmonary vascular resistance; SVR, systemic vascular resistance; $\mathrm{SvO}_{2}$, mixed venous oxygen saturation; Lac, plasma lactate; $\mathrm{PaO}_{2}$, arterial oxygen tension; $\mathrm{FiO}_{2}$, inspiratory oxygen fraction. ${ }^{\mathrm{a}} \mathrm{P}<0.001 \mathrm{vs}$. BASE1.

pulmonary artery pressure recordings and thermodilution measurements. A large bore femoral venous catheter was used for fluid administration, and a 5-F port (Intradyn; B. Braun Melsungen AG) in the femoral artery was used to insert an arterial catheter (cat. no. PV2015L20N; Pulsiocath; PULSION Medical Systems, Feldkirchen, Germany) for transpulmonary thermodilution measurements and pulse-contour analysis. Following insertion of catheters there was a 30 min recovery period. Blood gases were taken at every measuring time point from the arterial, central venous and pulmonary artery catheter.

Ventricular, arterial and venous pressure signals were digitised at $500 \mathrm{~Hz}$, analysed online using a multichannel recording software (ioX2; version 2.5.1.3; emka TECHNOLOGIES, Paris, France). The means of pressure values of a measurement period of 1 min were taken.

Drug preparation. For intravenous administration of BAY 41-8543 1.2 or $1.8 \mathrm{mg}$ of dry powder was dissolved in $10 \mathrm{ml}$ of solvent (45 g glycerol, $75 \mathrm{~g}$ aqua, $711.75 \mathrm{~g}$ polyethyleneglycol 400), as previously described (16), and diluted with 10 or $20 \mathrm{ml}$ of water, respectively. This produced 0.6 and $1.2 \mathrm{mg}$ BAY 41-8543 solutions for intravenous administration over $30 \mathrm{~min}$ with an infusion pump. The solution for inhalation consisted of 6 or $12 \mathrm{mg}$ of BAY 41-8543 dissolved in $150 \mu \mathrm{l}$ DMSO (99.5\%), $2.5 \mathrm{ml}$ ethanol (99\%) and $5 \mathrm{ml}$ citric acid $(0.2 \%)$. The inhalation was performed with an ultrasonic nebulizer (multisonic InfraControl; Flores medical GmbH, Probstzella, Germany) connected directly to the tracheal tube. In animals receiving iNO, the flow rate was adjusted for a concentration of $20 \mathrm{ppm}$. Control animals received these solvents without BAY 41-8543.

Induction of septic shock. The study aimed to detect changes in PVR and CO. Cardiac preload was optimized in all animals by repeated steps of an infusion between 10 and $20 \mathrm{ml} \mathrm{kg}^{-1}$ 


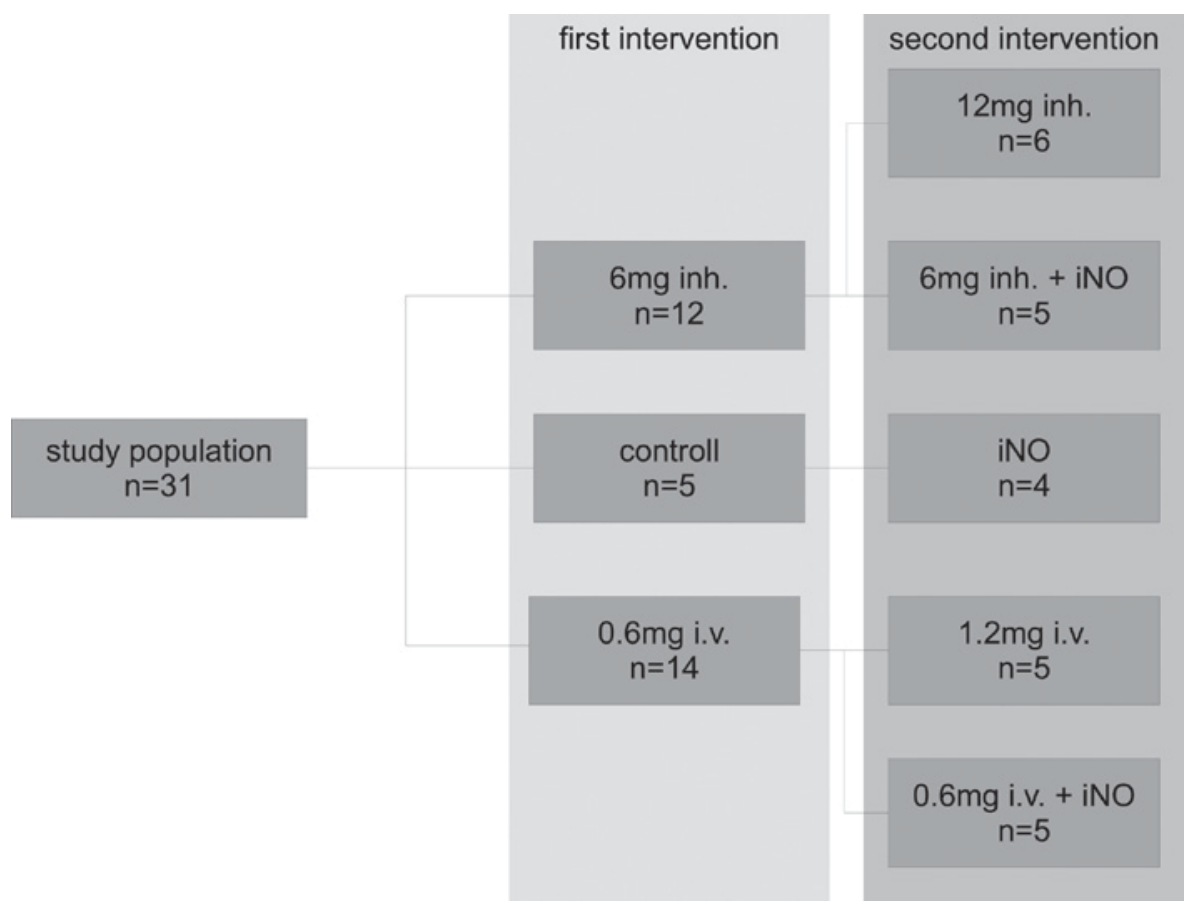

Figure 1. Experimental groupings, treatments and administration route. inh., inhalative administration of BAY 41-8543; i.v., intravenous administration of BAY 41-8543; iNO, inhaled nitrous oxide; $n$, number of animals.

6\% hydroxyethylstarch (Voluven; Fresenius Kabi, Ltd., Bad Homburg, Germany) then $0.9 \%$ sodium chloride for as long as the measured stroke volume variation (SVV) decreased and was $\geq 12 \%$. Following an initial baseline measurement (BASE1), endotoxic shock was induced by continuous intravenous infusion of lipopolysaccharides (LPS) from Escherichia coli O111:B4 (Sigma-Aldrich; Merck Millipore, Darmstadt, Germany), starting at $2 \mu \mathrm{g} \mathrm{kg}^{-1} \mathrm{~h}^{-1}$ for the first $\mathrm{h}$, then at $2 \mathrm{x}$ the previous rate, rising every $30 \mathrm{~min}$ until initiation of septic shock [mean arterial pressure (MAP) $<60 \mathrm{mmHg}$ ]. Then, the rate of LPS infusion was reduced to one-quarter of the last rate used to maintain septic shock and measurements (described previously) taken (SHOCK).

Septic shock therapy. Following SHOCK measurements, septic shock therapy was performed. Animals were continuously resuscitated with $0.9 \%$ sodium chloride fluid administration as guided by SVV (volume loading steps of $10 \mathrm{ml} \mathrm{kg}^{-1}$ to target a SVV $\leq 12 \%$ ) and central venous pressure (CVP) (no further loading if CVP increased while SVV did not decrease). In addition, fluid unresponsive animals were administered continuous intravenous norepinephrine as needed to maintain a MAP $\geq 60 \mathrm{mmHg}$, according to the Surviving Sepsis Campaign guidelines (17). Animals were measured (described previously) following haemodynamic stabilisation (RECOVERY).

Groupings. Following stabilization, animals were randomly allocated into the first intervention (IV1) or and second intervention (IV2) groups (Fig. 1). IV1 was further divided into three groups receiving the vehicle only (control), intravenous BAY 41-8543 (0.6 mg) or inhaled BAY 41-8543 (6 mg). IV2 was split into five subgroups receiving iNO alone, $0.6 \mathrm{mg}$ BAY 41-8543 intravenously or $6 \mathrm{mg}$ inhalatively with iNO (20 ppm), or 1.2 mg BAY 41-8543 intravenously or $12 \mathrm{mg}$ inhalatively.
Measurements (described previously) were taken every $15 \mathrm{~min}$ for $1 \mathrm{~h}$. Before continuing with the second intervention all animals were allowed a $1 \mathrm{~h}$ recovery period for drug clearance and another baseline measurement (BASE2) was taken.

Statistical analysis. Statistical analysis was performed using $\mathrm{R}$ software (version 2.0.12; R Foundation for Statistical Computing, Vienna, Austria). Normally distributed data (q-q plots, Shapiro test) were analysed using mixed model analysis of variance, followed by a post hoc Tukey's range test to statistically analyse changes over time during the $1 \mathrm{~h}$ measuring period. $\mathrm{P}<0.05$ was considered to indicate a statistically significant difference. Results are presented as the mean \pm the standard deviation.

\section{Results}

SHOCK and RECOVERY measurements. Induction of septic shock led to a significant decrease in CO and MAP $(\mathrm{P}<0.001$ vs. BASE1; Table I), while heart rate (HR) and PVR increased significantly $(\mathrm{P}<0.001$ vs. BASE1; Table I). Mixed venous oxygen saturation $\left(\mathrm{SvO}_{2}\right)$ significantly decreased and lactatemia (venous lactate $>2 \mathrm{mmol} / \mathrm{l}$ ) developed. The oxygenation index $\left(\mathrm{PaO}_{2} / \mathrm{FiO}_{2}\right)$ decreased significantly $(\mathrm{P}<0.001$ vs. BASE1; Table I). Septic shock therapy restored circulation, however, oxygenation remained severely impaired (Table II). Systemic vascular resistance (SVR) decreased to below BASE1 levels following septic shock therapy, however, although PVR was reduced to below SHOCK levels it was still above BASE1 levels.

IVI (intravenous and inhalative application). The haemodynamic changes observed in the group receiving $6 \mathrm{mg}$ inhaled BAY 41-8543 differed significantly from control 


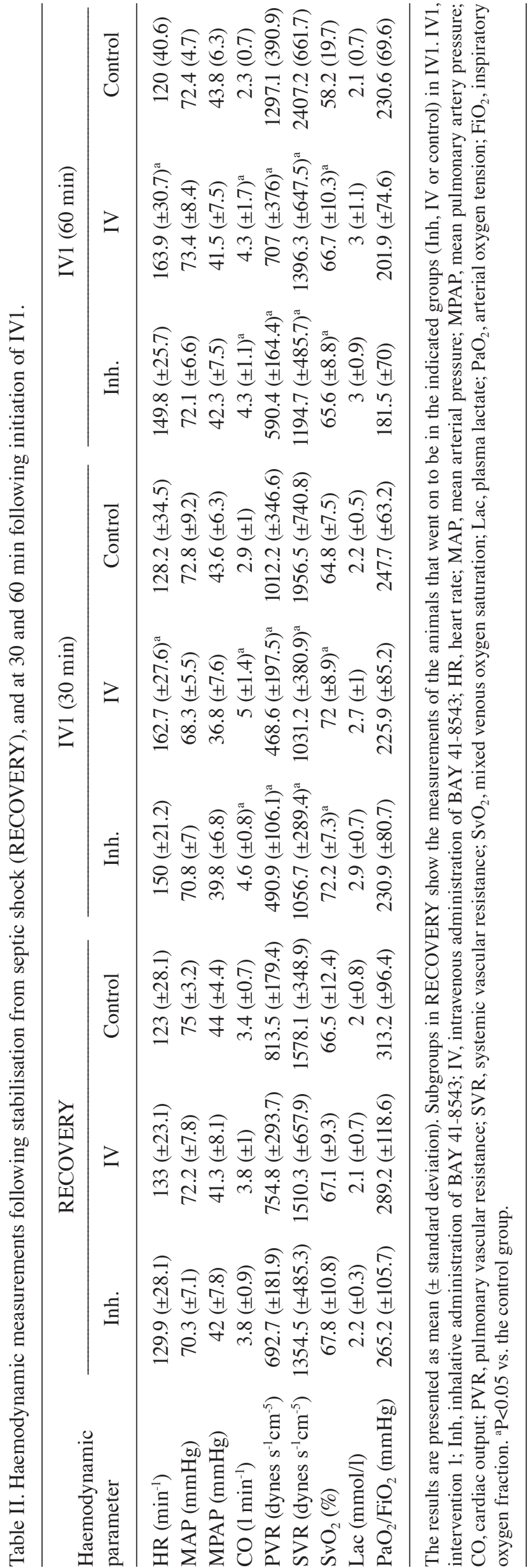




Table IV. Haemodynamic measurements prior to IV2 (BASE2), and at 30 and 60 min following initiation of IV2 with 2x BAY 41-8543.

\begin{tabular}{|c|c|c|c|c|c|c|}
\hline \multirow{2}{*}{$\begin{array}{l}\text { Haemodynamic } \\
\text { parameter }\end{array}$} & \multicolumn{2}{|c|}{ BASE2 } & \multicolumn{2}{|c|}{ IV2 (30 min) } & \multicolumn{2}{|c|}{ IV2 (60 min) } \\
\hline & Inh. $2 x$ & IV $2 x$ & Inh. $2 \mathrm{x}$ & IV $2 x$ & Inh. $2 x$ & IV $2 x$ \\
\hline $\operatorname{HR}\left(\min ^{-1}\right)$ & $140.5( \pm 34.8)$ & $178.7( \pm 32.9)$ & $140.3( \pm 35.3)$ & $170.8( \pm 29)$ & $146( \pm 35)$ & $176.4( \pm 37.5)$ \\
\hline MAP (mmHg) & $73.8( \pm 14.5)$ & $73.9( \pm 10.6)$ & $74.5( \pm 6.4)$ & $67.6( \pm 14.4)$ & $75.8( \pm 6.5)$ & $72.4( \pm 10.7)$ \\
\hline MPAP (mmHg) & $43.5( \pm 9.1)$ & $44.3( \pm 10.2)$ & $41.8( \pm 9.5)$ & $40.4( \pm 15.7)$ & $39.4( \pm 9.7)$ & $32.6( \pm 6.2)$ \\
\hline $\mathrm{CO}\left(1 \mathrm{~min}^{-1}\right)$ & $3.2( \pm 1.4)$ & $3.5( \pm 1.9)$ & $3.7( \pm 1.7)$ & $4.3( \pm 2.8)$ & $4( \pm 1.3)$ & $4.4( \pm 2)$ \\
\hline PVR (dynes s $\mathrm{s}^{-1} \mathrm{~cm}^{-5}$ ) & $888.7( \pm 454.7)$ & $1003.8( \pm 766.4)$ & $691.2( \pm 321.7)$ & $848.6( \pm 815)$ & $572.9( \pm 260.2)$ & $484.9( \pm 262.5)$ \\
\hline SVR (dynes s-1 $\mathrm{cm}^{-5}$ ) & $1731.2( \pm 713.3)$ & $1735.8( \pm 871.6)$ & $1426.7( \pm 446.9)$ & $1179.7( \pm 453.4)$ & $1296.4( \pm 331.6)$ & $1305.8( \pm 587.7)$ \\
\hline $\mathrm{SvO}_{2}(\%)$ & $59.6( \pm 13.1)$ & $59.4( \pm 14.6)$ & $57.3( \pm 17.5)$ & $51.9( \pm 24.2)$ & $55.9( \pm 10.4)$ & $65.2( \pm 8.9)$ \\
\hline $\mathrm{Lac}(\mathrm{mmol} / \mathrm{l})$ & $3.2( \pm 1.5)$ & $3.8( \pm 1.5)$ & $3.5( \pm 1.8)$ & $4.9( \pm 2.4)$ & $3.1( \pm 1.8)$ & $3.3( \pm 2.3)$ \\
\hline $\mathrm{PaO}_{2} / \mathrm{FiO}_{2}(\mathrm{mmHg})$ & $132( \pm 64.7)$ & $195.5( \pm 100.6)$ & $129.3( \pm 62.9)$ & $208.2( \pm 102.7)$ & $107.8( \pm 50.6)$ & $204( \pm 73.9)$ \\
\hline
\end{tabular}

The results are presented as mean ( \pm standard deviation). IV2, intervention 2; iNO, inhaled nitrous oxide; Inh, inhalative administration of BAY 41-8543; IV, intravenous administration of BAY 41-8543; HR, heart rate; MAP, mean arterial pressure; MPAP, mean pulmonary artery pressure; $\mathrm{CO}$, cardiac output; $\mathrm{PVR}$, pulmonary vascular resistance; $\mathrm{SVR}$, systemic vascular resistance; $\mathrm{SvO}_{2}$, mixed venous oxygen saturation; Lac, plasma lactate; $\mathrm{PaO}_{2}$, arterial oxygen tension; $\mathrm{FiO}_{2}$, inspiratory oxygen fraction.
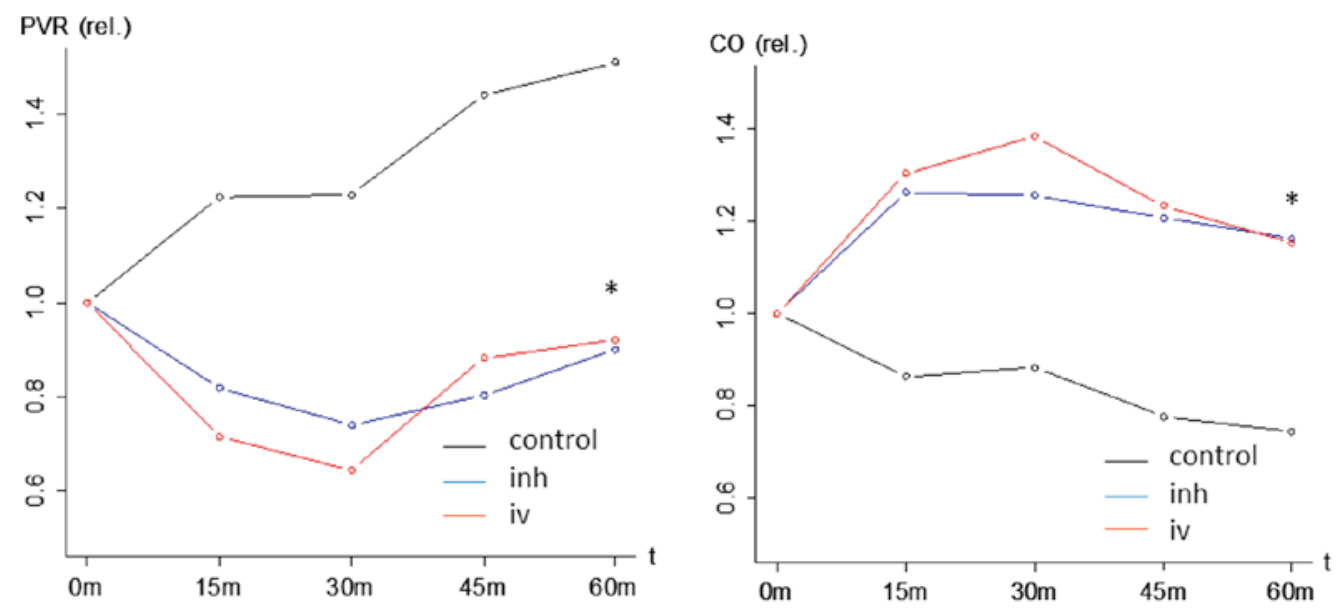

Figure 2. Changes in (A) CO and (B) PVR during septic shock with $6 \mathrm{mg}$ inhalative and $0.6 \mathrm{mg}$ intravenous BAY 41-8543 treatment. Mean relative change compared with the control group. ${ }^{\mathrm{P}}<0.05$ changes in $\mathrm{CO}$ and PVR during the $1 \mathrm{~h}$ measuring period in the study group vs. changes in the control group. CO, cardiac output; PVR, pulmonary vascular resistance; ctrl, control; inh., inhalative administration of BAY 41-8543; i.v., intravenous administration of BAY 41-8543.

animals (Table II). During administration of BAY 41-8543, CO (Fig. 2A) increased as PVR (Fig. 2B) and SVR (Table II) dropped (all $\mathrm{P}<0.05$ vs. the control group). HR did not differ significantly from control animals, while $\mathrm{SvO}_{2}$ was significantly higher $(\mathrm{P}>0.05$ and $\mathrm{P}<0.05$, respectively; Table II). There was no difference in oxygenation. Intravenous administration of 0.6 mg BAY 41-8543 had similar hemodynamic effects as inhalative administration of $6 \mathrm{mg}$ (Table II and Fig. 2). CO (Fig 2A) increased, while PVR (Fig. 2B) and SVR (Table II) decreased. However, HR was significantly increased compared with the control group $(\mathrm{P}<0.05$; Table II).

IV2 (addition of nitric oxide vs. increased dosage). Treatment with iNO, with or without $6 \mathrm{mg}$ inhalative or $0.6 \mathrm{mg}$ intravenous BAY 41-8543, resulted in significantly increased oxygenation ( $\mathrm{P}<0.001$ vs. BASE2; Table III). Between the groups receiving
iNO or iNO BAY 41-8543 (0.6 mg intravenous or $6 \mathrm{mg}$ inhaled) there were no significant differences in the haemodynamic parameters measured (Table III). Increasing the dosage of BAY 41-8543 (1.2 mg intravenous or $12 \mathrm{mg}$ inhaled) had a similar effect on the haemodynamic parameters measured compared with the combination of BAY 41-8543 (0.6 mg intravenous or $6 \mathrm{mg}$ inhaled) + iNO or iNO alone (Tables III and IV). Intravenous application of 1.2 mg BAY 41-8543 increased $\mathrm{SvO}_{2}$ compared with iNO alone or intravenous $0.6 \mathrm{mg}$ BAY 41-8543 + iNO (Tables III and IV).

\section{Discussion}

In endotoxic shock, intravenous or inhaled administration of BAY 41-8543 significantly decreased PVR and increased CO. The addition of iNO did not produce a significant difference in 
the haemodynamic parameters measured compared with BAY 41-8543 (intravenous or inhaled) alone.

The increase in CO during administration of BAY 41-8543 was a result of an increased stroke volume, as HR was not significantly altered compared with the control group. Previous studies investigating the effect of BAY 41-8543 on cardiac contractility reported heterogeneous results. Increased cGMP levels after stimulation of the $\mathrm{SGC}$, as it is achieved with $\mathrm{NO}$ or BAY 41-8543, have been reported to have minor negative (18) or positive inotropic effects (19). In addition, stimulators of the sGC such as NO or Bay 41-8543 may produce positive inotropic effects by affecting cAMP levels through crosstalk mediated by phosphodiesterase 2 (20), 3 (21) or $5(22,23)$. Therefore, an increase in cardiac contractility may have contributed to the increase in $\mathrm{CO}$ seen in the present study. However, with algorithm-guided volume therapy and a decrease in PVR and SVR, increased CO is primarily a consequence of cardiac afterload reduction.

NO is a physiological stimulator sGC. Plasma NO levels are typically increased in endotoxemia and sepsis, leading to vasodilation or, in severe cases, vasoplegia (24). The results of the present study indicate that additional pharmacological stimulation of sGC with BAY 41-8543 further increases vasodilation, particularly is more. A dose-dependent vasodilatory effect of BAY 41-8543 has been reported previously $(25,26)$. In the current study, the positive effects of BAY 41-8543 (intravenous and inhaled) on PVR and CO were not significantly different when the dose was doubled. This may be due to the severity of the septic shock induced in the present study, in which the animals exhibited a pronounced vasodilatation (due to endogenous NO release), capillary leakage and lung oedema (reflected by impaired gas diffusion). In this context, it is remarkable and of clinical importance that the inhalation of BAY 41-8543 still showed any effect at oxygenation indices below $200 \mathrm{mmHg}$. These results indicate that BAY 41-8543 still diffuses to the lung endothelium in severe lung oedema.

In the present study, intravenous and inhaled BAY 41-8543 were as effective as iNO, in respect to increased pulmonary vasodilation. However, iNO had an additional positive effect on oxygenation. Considering the adverse effect of discontinuing iNO, which was observed in the majority of patients by Christenson et al (27), there remain doubts that septic patients benefit from ventilation with iNO in the long term. Stimulation of sGC with drugs, such as BAY 41-8543, represents an alternative treatment to iNO. The combination of iNO and BAY 41-8543 (intravenous or inhaled) did not further decrease PVR. This may be due to $\mathrm{sGC}$ reaching maximum stimulation with one drug alone. However, the dose range of inhaled BAY 41-8543 chosen in the present study (from 6 to $12 \mathrm{mg}$ dissolved in ethanol) has been reported to have only an intermediate effect on sGC and PVR (26), and the effect of BAY 41-8543 is dependent on the presence of NO (28). Evgenov et al (26) reported a synergistic effect of BAY 41-8543 and iNO on pulmonary vasodilation. High endogenous NO levels in septic shock may explain why administration of exogenous NO together with BAY 41-8543 had no additional effect on PVR, whereas increasing the dosage of BAY 41-8543 did further decrease PVR.

Sepsis is a dynamic process, which must be considered when interpreting results. The present study meets this challenge by taking multiple measurements over time and performing statistical analysis of the complete course for differences between groups. However, since the animals' condition worsened during the experiment, the baseline measurements following resuscitation (RECOVERY) and prior to the second intervention (BASE2) were different.

In conclusion, the results of the present study identified that BAY 41-8543, a stimulator of sGC, reduces PVR and increases $\mathrm{CO}$ in experimental septic shock. In addition, there were no significant differences identified in the clinical effects of inhaled and intravenous administration routes. Previously, the inhalation of BAY 41-8543 has typically been performed using microparticles, for deep lung penetration and complete nebulisation (26). The results of the present study show that BAY 41-8543 can be nebulized in a solution and produce similar effects.

\section{Acknowledgements}

The research grant, study medication and personnel expenses were provided by Bayer Pharma AG (Wuppertal, Germany).

\section{References}

1. Stasch JP, Pacher P and Evgenov OV: Soluble guanylate cyclase as an emerging therapeutic target in cardiopulmonary disease. Circulation 123: 2263-2273, 2011.

2. Hampl V and Herget J: Role of nitric oxide in the pathogenesis of chronic pulmonary hypertension. Physiol Rev 80: 1337-1372, 2000.

3. Evgenov OV, Ichinose F, Evgenov NV, Gnoth MJ, Falkowski GE, Chang Y, Bloch KD and Zapol WM: Soluble guanylate cyclase activator reverses acute pulmonary hypertension and augments the pulmonary vasodilator response to inhaled nitric oxide in awake lambs. Circulation 110: 2253-2259, 2004.

4. Egemnazarov B, Sydykov A, Schermuly RT, Weissmann N, Stasch JP, Sarybaev AS, Seeger W, Grimminger F and Ghofrani HA: Novel soluble guanylyl cyclase stimulator BAY 41-2272 attenuates ischemia-reperfusion-induced lung injury. Am J Physiol Lung Cell Mol Physiol 296: L462-L469, 2009.

5. Ghofrani HA, Galie N, Grimminger F, Grunig E, Humbert M, Jing ZC, Keogh AM, Langleben D, Kilama MO, Fritsch A, et al: Riociguat for the treatment of pulmonary arterial hypertension. N Engl J Med 369: 330-340, 2013.

6. Ghofrani HA, D'Armini AM, Grimminger F, Hoeper MM, Jansa P, Kim NH, Mayer E, Simonneau G, Wilkins MR, Fritsch A, et al: Riociguat for the treatment of chronic thromboembolic pulmonary hypertension. N Engl J Med 369: 319-329, 2013.

7. Lapp H, Mitrovic V, Franz N, Heuer H, Buerke M, Wolfertz J, Mueck W, Unger S, Wensing G and Frey R: Cinaciguat (BAY 58-2667) Improves cardiopulmonary hemodynamics in patients with acute decompensated heart failure. Circulation 119: 2781-2788, 2009.

8. Dumitrascu R, Weissmann N, Ghofrani HA, Dony E, Beuerlein K, Schmidt H, Stasch JP, Gnoth MJ, Seeger W, Grimminger F and Schermuly RT: Activation of soluble guanylate cyclase reverses experimental pulmonary hypertension and vascular remodeling. Circulation 113: 286-395, 2006.

9. Geschka S, Kretschmer A, Sharkovska Y, Evgenov OV, Lawrenz B, Hucke A, Hocher B and Stasch JP: Soluble guanylate cyclase stimulation prevents fibrotic tissue Remodelling and improves survival in salt-sensitive dahl rats. PLoS One 6: e21853, 2011.

10. Hoeper MM and Granton J: Intensive care unit management of patients with severe pulmonary hypertension and right heart failure. Am J Respir Crit Care Med 184: 1114-1124, 2011.

11. Cernacek P and Stewart DJ: Immunoreactive endothelin in human plasma: Marked elevations in patients in cardiogenic shock. Biochem Biophys Res Commun 161: 562-567, 1989.

12. Sheehan F and Redington A: The right ventricle: Anatomy, physiology and clinical imaging. Heart 94: 1510-1515, 2008. 
13. Ventetuolo CE and Klinger JR: Management of acute right ventricular failure in the intensive care unit. Ann Am Thorac Soc 11: 811-822, 2014.

14. Guide for the Care and Use of Laboratory Animals. 8th edition. National Academies Press, Washington, DC, 2011.

15. Ventilation with lower tidal volumes as compared with traditional tidal volumes for acute lung injury and the acute respiratory distress syndrome. The acute respiratory distress syndrome network. N Engl J Med 342: 1301-1308, 2000.

16. Stasch J, Dembowsky K, Perzborn E, Stahl E and Schramm M: Cardiovascular actions of a novel NO-independent guanylyl cyclase stimulator, BAY 41-8543: In vivo studies. Brit J Pharmacol 135: 344-355, 2002.

17. Dellinger RP, Levy MM, Carlet JM, Bion J, Parker MM, Jaeschke R, Reinhart K, Angus DC, Brun-Buisson C, Beale R, et al: Surviving sepsis campaign: International guidelines for management of severe sepsis and septic shock: 2008. Crit Care Med 36: 296-327, 2008.

18. Cawley SM, Kolodziej S, Ichinose F, Brouckaert P, Buys ES and Bloch KD: sGC\{alpha\}1 mediates the negative inotropic effects of NO in cardiac myocytes independent of changes in calcium handling. Am J Physiol Heart Circ Physiol 301: H157-H163, 2011.

19. Sarkar D, Vallance P, Amirmansour C and Harding SE: Positive inotropic effects of NO donors in isolated guinea-pig and human cardiomyocytes independent of NO species and cyclic nucleotides. Cardiovasc Res 48: 430-439, 2000.

20. Zaccolo M and Movsesian MA: cAMP and cGMP signaling cross-talk: Role of phosphodiesterases and implications for cardiac pathophysiology. Circ Res 100: 1569-1578, 2007.

21. Francis SH, Busch JL, Corbin JD and Sibley D: cGMP-dependent protein kinases and cGMP phosphodiesterases in nitric oxide and cGMP action. Pharmacol Rev 62: 525-563, 2010.
22. Nagendran J, Archer SL, Soliman D, Gurtu V, Moudgil R, Haromy A, St Aubin C, Webster L, Rebeyka IM, Ross DB, et al: Phosphodiesterase type 5 is highly expressed in the hypertrophied human right ventricle, and acute inhibition of phosphodiesterase type 5 improves contractility. Circulation 116: 238-248, 2007.

23. Shan X, Quaile MP, Monk JK, French B, Cappola TP and Margulies KB: Differential expression of PDE5 in failing and nonfailing human myocardium. Circ Heart Fail 5: 79-86, 2012.

24. Kilbourn RG, Jubran A, Gross SS, Griffith OW, Levi R, Adams J and Lodato RF: Reversal of endotoxin-mediated shock by NG-methyl-L-arginine, an inhibitor of nitric oxide synthesis. Biochem Biophys Res Commun 172: 1132-1138, 1990.

25. Stasch JP, Alonso-Alija C, Apeler H, Dembowsky K, Feurer A, Minuth T,Perzborn E, Schramm M and Straub A: Pharmacological actions of a novel NO-independent guanylyl cyclase stimulator, BAY 41-8543: In vitro studies. Brit J Pharmacol 135: 333-343, 2002.

26. Evgenov OV, Kohane DS, Bloch KD, Stasch JP, Volpato GP, Bellas E, Evgenov NV, Buys ES, Gnoth MJ, Graveline AR, et al: Inhaled agonists of soluble guanylate cyclase induce selective pulmonary vasodilation. Am J Respir Crit Care Med 176: 1138-1145, 2007.

27. Christenson J, Lavoie A, O'Connor M, Bhorade S, Pohlman A and Hall JB: The incidence and pathogenesis of cardiopulmonary deterioration after abrupt withdrawal of inhaled nitric oxide. Am J Respir Crit Care Med 161: 1443-1449, 2000.

28. Badejo AM Jr, Nossaman VE, Pankey EA, Bhartiya M, Kannadka CB, Murthy SN, Nossaman BD and Kadowitz PJ: Pulmonary and systemic vasodilator responses to the soluble guanylyl cyclase stimulator, BAY 41-8543, are modulated by nitric oxide. Am J Physiol Heart Circ Physiol 299: H1153-H1159, 2010. 